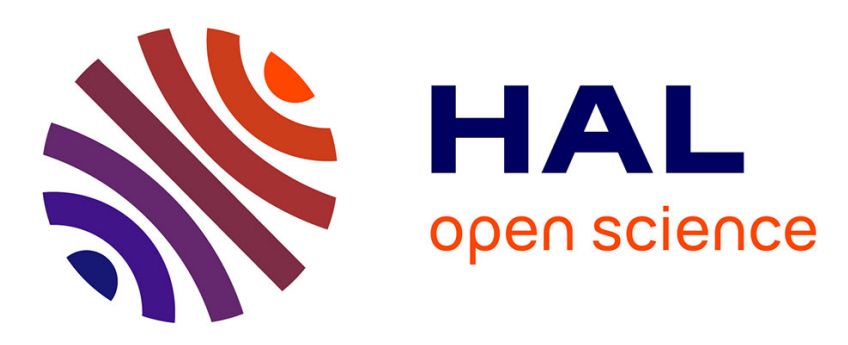

\title{
Influence of fluid-flow direction on effective permeability of the vertebral end plate: an analytical model
}

\author{
Pascal Swider, Franck Accadbled, Jean-Michel Laffosse, Jérôme Sales de
} Gauzy

\section{- To cite this version:}

Pascal Swider, Franck Accadbled, Jean-Michel Laffosse, Jérôme Sales de Gauzy. Influence of fluid-flow direction on effective permeability of the vertebral end plate: an analytical model. Computer Methods in Biomechanics and Biomedical Engineering, 2012, 15 (2), pp.151-156. 10.1080/10255842.2010.518960 . hal-01589888

\section{HAL Id: hal-01589888 \\ https://hal.science/hal-01589888}

Submitted on 19 Sep 2017

HAL is a multi-disciplinary open access archive for the deposit and dissemination of scientific research documents, whether they are published or not. The documents may come from teaching and research institutions in France or abroad, or from public or private research centers.
L'archive ouverte pluridisciplinaire HAL, est destinée au dépôt et à la diffusion de documents scientifiques de niveau recherche, publiés ou non, émanant des établissements d'enseignement et de recherche français ou étrangers, des laboratoires publics ou privés. 


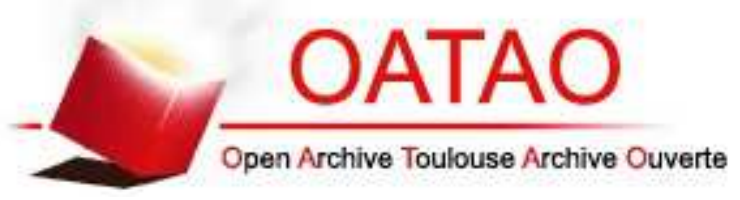

\section{Open Archive TOULOUSE Archive Ouverte (OATAO)}

OATAO is an open access repository that collects the work of Toulouse researchers and makes it freely available over the web where possible.

This is an author-deposited version published in : http://oatao.univ-toulouse.fr/ Eprints ID : 18178

To link to this article : DOI: $10.1080 / 10255842.2010 .518960$

URL : http://dx.doi.org/10.1080/10255842.2010.518960

To cite this version : Swider, Pascal and Accadbled, Franck and Laffosse, Jean-Michel and Sales de Gauzy, Jérôme Influence of fluid-flow direction on effective permeability of the vertebral end plate: an analytical model. (2012) Computer Methods in

Biomechanics and Biomedical Engineering, vol. 15 ( $\left.\mathrm{n}^{\circ} 2\right)$. pp. 151156. ISSN 1025-5842

Any correspondence concerning this service should be sent to the repository administrator: staff-oatao@ listes-diff.inp-toulouse.fr 


\title{
Influence of fluid-flow direction on effective permeability of the vertebral end plate: an analytical model
}

\author{
P. Swider ${ }^{\mathrm{a} *}$, F. Accadbled ${ }^{\mathrm{b}}$, J.M. Laffosse ${ }^{\mathrm{b}}$ and J. Sales de Gauzy ${ }^{\mathrm{a}}$ \\ ${ }^{a}$ IMFT UMR CNRS 5502, University of Toulouse, Toulouse, France; ${ }^{b}$ Service d'Orthopédie, Hôpital des Enfants, CHU de Toulouse, \\ Toulouse, France
}

\begin{abstract}
Convective transports in the vertebral end plate (VEP) play a significant role in the homeostasis of the spine. A few studies hypothesised that the hydraulic resistance or effective permeability of the VEP could be dependant upon fluid-flow direction. Results were influenced by species, region of interest within the end plate and pathology. Some results were contradictory. We propose an analytical model based on steady-state Newtonian flows in capillary media to develop a phenomenological analysis of convective transport through the VEP. This dependence was established using a biquadratic analytical function involving porosities of subchondral bone, capillary bed and cartilage end plate. Discussion of results provided a theoretical justification for variable and/or contradictory experimental results concerning the amount of energy lost by fluid during its course through the end plate. Tissue porosities and, especially, those relative to the capillary bed could strongly influence the dependence of fluid energy loss on flow direction and could potentially modify tissue homeostasis related to the day and night cycle.
\end{abstract}

Keywords: convective transport; permeability; hydraulic resistance; vertebral end plate; spine

\section{Introduction}

Solute transport contributing to the metabolic pathways of intervertebral disc (IVD) cells is induced by diffusion and convection. Convective transport is of utmost importance to large solutes such as glycosaminoglycanes, whereas diffusion drives the exchange of small solutes such as glucose, oxygen and lactate (Holm et al. 1981; Katz et al. 1986; Ferguson et al. 2004; Urban et al. 2004). In vivo phenomena involve coupling effects. The pumping effect due to day and night cycles plays a significant role in nutrient transport and waste clearance, while modifying diffusion gradients along with osmotic and electrical potentials (Bibby et al. 2005; Grunhagen et al. 2006; Soukane et al. 2007).

The annulus fibrosus periphery and the vertebral end plate (VEP) are the two pathways for nutrient transport by convection (Roberts et al. 1989; Houben et al. 1997), but the role of the VEP zone is preponderant. This nutritive pathway is vulnerable and IVD disorders generally show histological modifications of its constitutive tissue (Urban et al. 2004). Correlations between variation in transport properties of the VEP and IVD alteration have been detected by marked $\mathrm{pH}$ diminution in IVD presenting degenerative radiographic signs (Nachemson et al. 1970). This observation was later confirmed by studies showing that diminution of the permeability was modifying both diffusive and convective transports (Sélard et al. 2003; Ferguson et al. 2004).
Roberts et al. (1993) suggested that onset/progression of scoliosis may be a consequence of a disorder of VEP permeability. A decrease of nitrogen protoxide diffusion was observed in the convexity of neuromuscular scoliosis in vivo (Urban et al. 2001) and correlated with calcifications of the cartilage end plate (CEP) on radiographs. A decrease of VEP effective permeability was also quantified ex vivo at the apex of an experimental scoliosis in a porcine animal model (Laffosse 2008).

Because fluid migrates through a non-symmetrical biological tissue stacking sequence with different porosities, the question of dependence of energy loss on fluid to flow direction can be raised. The energy loss was expressed using the hydraulic resistance or the effective permeability of tissue. It was shown that it was dependant upon the type of investigated tissue (isolated CEP or global end plate), region of interest (disc level, central of peripheral zone of the VEP), pathological modification of the spine and species. In normal tissue, we demonstrated that results varied with growth (Accadbled 2007; Accadbled, Ambard et al. 2008; Accadbled, Laffosse et al. 2008) and flow direction (Ayotte et al. 2001; Laffosse et al. 2005; Accadbled, Laffosse et al. 2008). Pathology has a significant influence on VEP's properties (Rajasekaran et al. 2004). In a scoliosis animal model (Laffosse 2008; Odent et al. 2008), we highlighted some variations though not statistically significant. Contradictory results have also 
been reported (Ayotte et al. 2000; Ayotte et al. 2001; Laffosse et al. 2005).

Notwithstanding the role of fluid-flow direction on energy loss that has been quantified objectively with in vitro studies, the theoretical rationale is still an open problem. In this paper, we propose an analytical model based on steady state flows in capillaries to develop a phenomenological analysis of convective transport through the VEP. Then we evaluate how such a model could support a unified theoretical justification of multiple experimental results.

\section{Materials and methods}

The analytical model dealt with the convective transport through the VEP. Governing equations of transport were established assuming flows of Newtonian fluid with a low Reynolds number. The exchanges were isothermal, gravity effects were negligible and porous substrates were not deformable under fluid pressure. Governing equations were derived from the generalised Bernoulli's theorem (Idelchik 2001). Flow was investigated using a capillarytype model with evolving cross-sections and no physicochemical interactions with the interfaces. The model described in Figure 1 was established at the scale of a group of connected pores. Subchondral bone and CEP the crosssection of which were, respectively, $s_{\mathrm{b}}$ and $s_{\mathrm{c}}$ were connected by the capillary bed represented by a rectilinear micro channel of cross-section $s_{\mathrm{cb}}$ and length $l_{\mathrm{cb}}$. Flow in and flow out represented, respectively, flow from the vertebral body to the IVD (trajectory: A-B-C-D) and flow from the IVD to the vertebral body (trajectory: D-C-B-A).

\subsection{Governing equations}

The restriction of flow coming from the vertebral body generated an energy loss, which was associated with the difference in pressure between the flow in pressure $p_{\mathrm{sb}}$ (point $\mathrm{A}$ ) and the pressure $p_{\mathrm{cb}}$ in the capillary bed (point B). The differential pressure (or singular pressure drop) is expressed by the Darcy-Weisbach equation (1). It is dependant upon the square of the down stream fluid velocity after the cross-section restriction, the fluid density and an empirical shape coefficient limited to 0.6 (Rohsenhow 1985; Dullien 1992; Idelchik 2001). In the application to the VEP modelled in Figure $1, v_{\mathrm{cb}}$ is the fluid velocity into the connective capillary, $\rho_{\mathrm{f}}$ is the fluid density and $c_{\text {sb-cb }}$ is the shape coefficient relative to the flow restriction:

$$
p_{\mathrm{sb}}-p_{\mathrm{cb}}=\rho_{\mathrm{f}} v_{\mathrm{cb}}^{2}\left(1-c_{\mathrm{sb}-\mathrm{cb}}\right) .
$$

The flow into the capillary (point B, point $\mathrm{C}$ ) induced an energy loss described by the differential pressure (or regular pressure drop) as expressed by Equation (2). With a constant cross-section, the pressure drop is proportional to the fluid velocity (Rohsenhow 1985; Dullien 1992; Idelchik 2001). In our application, $v_{\mathrm{f}}$ is the fluid dynamic viscosity, $s_{\mathrm{cb}}$ is the cross-section of the capillary and $l_{\mathrm{cb}}$ is its length:

$$
\Delta p_{\mathrm{cb}}=\frac{8 \pi v_{\mathrm{f}} l_{\mathrm{cb}}}{s_{\mathrm{cb}}} v_{\mathrm{cb}}
$$

The flow opening into the cartilaginous layer induced the energy loss described by Equation (3) (Rohsenhow 1985; Dullien 1992; Idelchik 2001). This equation expresses the (a)

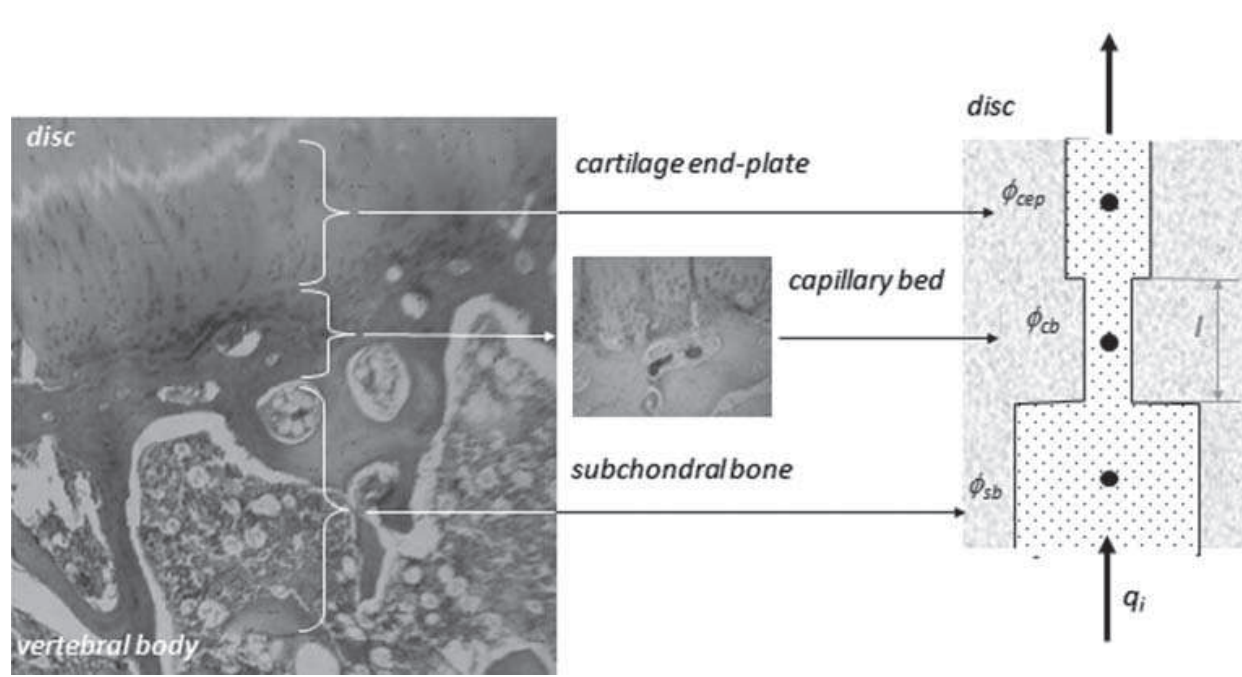

(b)

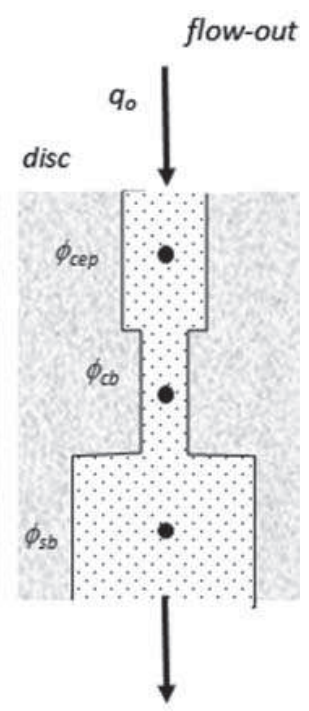

Figure 1. (a) Histological slice showing the stacking sequence of subchondral bone, capillary bed and CEP (Laffosse 2008). (b) Capillary model representing the convective exchanges between IVD and vertebral body. 'Flow-in' (rate $q_{\mathrm{i}}$ ) described the fluid motion from the vertebral body towards the disc; 'flow-out' (rate $q_{\mathrm{o}}$ ) described the fluid motion from the disc towards the vertebral body. In the zone of interest, the simplified model of the capillary bed was a tubular micro channel of length $l_{\mathrm{cb}}$ associated with the porosity $\phi_{\mathrm{cb}}$. 
differential pressure (or singular pressure drop) measured between point $\mathrm{C}\left(p_{\mathrm{cb}}\right)$ and point $\mathrm{D}\left(p_{\text {cep }}\right)$. The flow-out cross-section is $s_{\text {cep. }}$. The pressure drop is proportional to the square of the fluid velocity in the larger section and the shape coefficient depends on the ratio of cross-sections (Rohsenhow 1985; Dullien 1992; Idelchik 2001):

$$
p_{\mathrm{cb}}-p_{\mathrm{cep}}=\rho_{\mathrm{f}} v_{\mathrm{cb}}^{2} \frac{s_{\mathrm{cb}}}{s_{\mathrm{cep}}}\left(1-\frac{s_{\mathrm{cb}}}{s_{\mathrm{cep}}}\right) .
$$

The overall relative pressure $\Delta p_{\text {flow-in }}$ expresses the energy lost by the fluid. It is the sum of the three successive losses expressed by Equations (1)-(3), and this results in Equation (4):

$$
\begin{aligned}
\Delta p_{\text {flow }- \text { in }}= & p_{\text {sb }}-p_{\text {cep }}=\frac{8 \pi v_{\mathrm{f}} l_{\mathrm{cb}}}{s_{\mathrm{cb}}} v_{\mathrm{cb}} \\
& +\rho_{\mathrm{f}} v_{\mathrm{cb}}^{2}\left[\frac{s_{\mathrm{cb}}}{s_{\mathrm{cep}}}-\left(\frac{s_{\mathrm{cb}}}{s_{\mathrm{cep}}}\right)^{2}+1-c_{\mathrm{sbcb}}^{-1}\right] .
\end{aligned}
$$

The ratio of pressure $\Delta p_{\text {flow-in }}$ by flow rate $q_{\mathrm{i}}$ is the overall hydraulic resistance $R_{\mathrm{i}}$ opposed to the fluid in its course through the stacking sequence of tissue: subchondral bone, capillary bed and CEP. The reciprocal expression of hydraulic resistance is the effective permeability $\kappa_{\mathrm{i}}$ at Darcy scale. The flow rate is constant whatever the zone of interest and we used the flow rate into the capillary bed, i.e. $q_{\mathrm{i}}=s_{\mathrm{cb}} \cdot v_{\mathrm{cb}}$. Finally, Equation (4) was modified to obtain the expression of hydraulic resistance and effective permeability in flow-in in the form of Equation (5):

$$
\begin{aligned}
R_{\mathrm{i}}= & \kappa_{\mathrm{i}}^{-1}=\frac{\Delta p_{\mathrm{flow}-\mathrm{in}}}{q_{\mathrm{i}}}=\frac{8 \pi v_{\mathrm{f}} l_{\mathrm{cb}}}{s_{\mathrm{cb}}^{2}} \\
& +\frac{\rho_{\mathrm{f}} q_{\mathrm{i}}}{s_{\mathrm{cb}}^{2}}\left[\frac{s_{\mathrm{cb}}}{s_{\mathrm{cep}}}-\left(\frac{s_{\mathrm{cb}}}{s_{\mathrm{cep}}}\right)^{2}+1-c_{\mathrm{sb}-\mathrm{cb}}^{-1}\right] .
\end{aligned}
$$

A similar methodology was used to obtain the flow-out hydraulic resistance $R_{\mathrm{O}}$ and the effective permeability $\kappa_{\mathrm{o}}$. In this configuration, the flow direction was CEP capillary bed - subchondral bone. Equation (1) involving the updated shape coefficient $c_{\text {cep-cb }}$ described the pressure loss due to the restriction of flow between the CEP (point D) and the capillary bed (point C). Equation (2) was unchanged to express the energy loss between the capillary bed (point C) and capillary bed (point B). Equation (3) is used to express the energy loss when the fluid is flowing from the capillary bed (point B) to the subchondral bone (point A), with $s_{\text {cep }}$ replaced by $s_{\mathrm{sb}}$. Finally, hydraulic resistance and effective permeability in flow-out are given by Equation (6):

$$
\begin{aligned}
R_{\mathrm{o}}= & \kappa_{\mathrm{o}}^{-1}=\frac{\Delta p_{\text {flow }- \text { out }}}{q_{\mathrm{o}}}=\frac{p_{\text {cep }}-p_{\mathrm{sb}}}{q_{\mathrm{o}}}=\frac{8 \pi v_{\mathrm{f}} l_{\mathrm{cb}}}{s_{\mathrm{cb}}^{2}} \\
& +\frac{\rho_{\mathrm{f}} q_{\mathrm{o}}}{s_{\mathrm{cb}}^{2}}\left[\frac{s_{\mathrm{cb}}}{s_{\mathrm{sb}}}-\left(\frac{s_{\mathrm{cb}}}{s_{\mathrm{sb}}}\right)^{2}+1-c_{\text {cep-cb }}^{-1}\right] .
\end{aligned}
$$

To take into account a group of capillaries in a zone of interest, we assumed that the distribution pattern of interconnected pores is homogenous and the flow rate is identical in all capillaries of the zone. This allowed replacing the cross-sections $s_{\mathrm{sb}}, s_{\mathrm{cep}}$ and $s_{\mathrm{cb}}$ in Equations (5) and (6) with the subchondral bone porosity $\phi_{\mathrm{sb}}$, the CEP porosity $\phi_{\text {cep }}$ and the capillary bed porosity $\phi_{\mathrm{cb}}$, respectively. The difference of Equation (5) and Equation (6) resulted in Equation (7) expressing the influence on fluid-flow direction upon the hydraulic resistance and effective permeability at the capillary scale:

$$
\Delta R=R_{\mathrm{o}}-R_{\mathrm{i}}=\kappa_{\mathrm{o}}^{-1}-\kappa_{\mathrm{i}}^{-1}=\frac{\rho_{\mathrm{f}}}{s_{\mathrm{cb}}^{2}} q_{\mathrm{i}}\left(\alpha \beta_{\mathrm{o}}-\beta_{\mathrm{i}}\right),
$$

with

$$
\begin{aligned}
& \beta_{\mathrm{i}}=\left(\frac{\phi_{\mathrm{cb}}}{\phi_{\mathrm{cep}}}\right)-\left(\frac{\phi_{\mathrm{cb}}}{\phi_{\mathrm{cep}}}\right)^{2}+1-c_{\mathrm{sb}-\mathrm{cb}}^{-1} \\
& \beta_{\mathrm{o}}=\left(\frac{\phi_{\mathrm{cb}}}{\phi_{\mathrm{sb}}}\right)-\left(\frac{\phi_{\mathrm{cb}}}{\phi_{\mathrm{sb}}}\right)^{2}+1-c_{\mathrm{cep}-\mathrm{cb}}^{-1} \text { and } \alpha=\frac{q_{\mathrm{o}}}{q_{\mathrm{i}}} .
\end{aligned}
$$

We assumed that in quasi-static behaviour, flow-in and flow-out rates were identical, i.e. $\alpha=1$. Flow dependence on shape coefficients was of second order and $c_{\text {sb-cb }} \approx c_{\text {cep-cb. }}$. These supplementary hypotheses allow transforming Equation (7) into the biquadratic Equation (8), where two variables were introduced: $a$ expressed the ratio of capillary bed porosity $\phi_{\mathrm{cb}}$ over the subchondral bone porosity $\phi_{\mathrm{sb}}$ and $b$ expressed the ratio of capillary bed porosity $\phi_{\mathrm{cb}}$ over CEP porosity $\phi_{\text {cep }}$. Fluid viscosity $\rho_{\mathrm{f}}$, capillary bed cross-section $s_{\mathrm{cb}}$ and flow rate $q_{\mathrm{i}}$ were controlled parameters. Finally, the investigation of the dependence of hydraulic resistance and effective permeability on the VEP to fluid-flow direction consisted in studying the evolution of function $\Delta \beta$ :

$$
\begin{aligned}
\Delta R & =R_{\mathrm{o}}-R_{\mathrm{i}}=\frac{\rho_{\mathrm{f}}}{s_{\mathrm{cb}}^{2}} q_{\mathrm{i}}\left(\beta_{\mathrm{o}}-\beta_{\mathrm{i}}\right)=\delta \Delta \beta \\
& =\delta(a-b)(1-a-b),
\end{aligned}
$$

with

$$
a=\frac{\phi_{\mathrm{cb}}}{\phi_{\mathrm{sb}}}, \quad b=\frac{\phi_{\mathrm{cb}}}{\phi_{\mathrm{cep}}} \text { and } \delta=\frac{\rho_{\mathrm{f}}}{s_{\mathrm{cb}}^{2}} q_{\mathrm{i}} .
$$

\section{Results}

Governing Equation (8) describing the dependence of energy loss on fluid-flow direction is plotted in Figure 2. First, it appeared that two groups of singular values, $b_{0}=1-a$ and $b_{0}=a$, could cancel $\Delta \beta$. The intersection of these groups of solutions is $b_{0}=a=0.5$. As the porosity of the CEP $\phi_{\text {cep }}$ is a priori lower than that of subchondral bone $\phi_{\mathrm{sb}}, b$ is strictly lower than $a$. The definition domain of function $\Delta \beta$ is $a \in] 0 ; 1]$ and $b \in] a ; 1]$. 


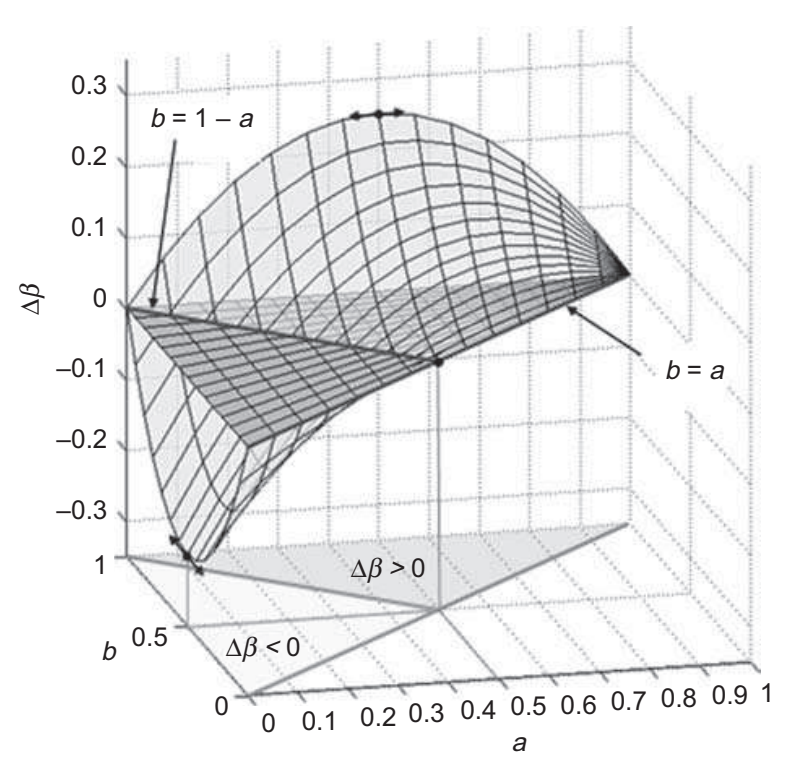

Figure 2. Function $\Delta \beta$ described the dependence of energy loss on fluid-flow direction in the form of a biquadratic function of porosity ratios $(a, b) ; a$ is the ratio of capillary bed porosity $\phi_{\mathrm{cb}}$ over subchondral bone porosity $\phi_{\mathrm{sb}}$, and $b$ is the ratio of capillary bed porosity $\phi_{\mathrm{cb}}$ over CEP porosity $\phi_{\text {cep }}$.

For $a \in] 0 ; 0.5]$ and $b \in] a ; 1-a], \Delta \beta$ was negative which meant that the hydraulic resistance in flow-out was superior to that in flow-in, i.e. $R_{\mathrm{o}}>R_{\mathrm{i}}$. Effective permeability followed the reverse relationship, i.e. $\kappa_{\mathrm{o}}<\kappa_{\mathrm{i}}$. Opposite results were obtained for $a \in] 0 ; 0.5]$ and $b \in$ ] $1-a ; 1]$ and for $a \in] 0.5 ; 1]$ and $b \in] a ; 1]$. Positive value of $\Delta \beta$ described a weaker effective permeability in flow-out compared to that in flow-in, i.e. $\kappa_{\mathrm{O}}>\kappa_{\mathrm{i}}$ and $R_{\mathrm{o}}<R_{\mathrm{i}}$.

Secondly, values that cancelled the first derivative of $\Delta \beta$ referring to $a$ were $a=0.5$ whatever be the value of $b$ with $\Delta \beta$ positive. Similarly, nil first derivative referring to $b$ was obtained for $b=0.5$ whatever be the value of $a$, with $\Delta \beta$ negative. As shown in Figure 2, greater absolute values of $\Delta \beta$ were obtained for these particular values of $a$ and $b$.

We found that alternation of $\Delta \beta$ sign describing the dependence of energy loss on flow direction was obtained for the particular value $b_{0}=1-a$. When $b_{0}$ and $a$ were replaced by their value, a relationship between tissue porosities of the VEP was obtained. This is expressed by Equation (9) in which we introduced $\varepsilon$ representing the ratio of CEP porosity over the subchondral bone porosity. Physiologically, $\varepsilon$ was much lower than 1 , and this allowed the linearisation in $\varepsilon$ of Equation (9) to be obtained by implementing a Taylor expansion at the first order:

$$
\begin{aligned}
\phi_{\mathrm{cb}} & =\phi_{\mathrm{cep}}(1+\varepsilon)^{-1} \\
& \approx \phi_{\mathrm{cep}}(1-\varepsilon)+O\left(\varepsilon^{2}\right) \text { with } \varepsilon=\frac{\phi_{\mathrm{cep}}}{\phi_{\mathrm{sb}}} \ll 1 .
\end{aligned}
$$

Equation (9) associated with the solutions of Equation (8) allowed highlighting the role of capillary bed porosity $\phi_{\mathrm{cb}}$ in energy loss, hydraulic resistance and effective permeability of the VEP. As expressed by Equation (10a), it was found that effective permeability of the VEP might be independent of fluid-flow direction for a threshold value of $\phi_{\mathrm{cb}}$. Alternatively, perturbations of capillary bed porosity might induce flow-direction dependence as shown in Equations (10b) and (10c):

$$
\begin{aligned}
\text { if } \phi_{\mathrm{cb}} & =\phi_{\mathrm{cep}}(1-\varepsilon), \\
\text { then } b & =b_{0} \Leftrightarrow \Delta \beta=0, \text { so } R_{\mathrm{o}}=R_{\mathrm{i}} \text { and } \kappa_{\mathrm{o}}=\kappa_{\mathrm{i}} ;
\end{aligned}
$$

$$
\begin{aligned}
\text { if } \phi_{\mathrm{cb}} & \leq \phi_{\mathrm{cep}}(1-\varepsilon), \\
\text { then } b & <b_{0} \Leftrightarrow \Delta \beta<0, \text { so } R_{\mathrm{o}}<R_{\mathrm{i}} \text { and } \kappa_{\mathrm{o}}>\kappa_{\mathrm{i}} ; \\
\text { if } \phi_{\mathrm{cb}} & >\phi_{\mathrm{cep}}(1-\varepsilon), \\
\text { then } b & >b_{0} \Leftrightarrow \Delta \beta>0, \text { so } R_{\mathrm{o}}>R_{\mathrm{i}} \text { and } \kappa_{\mathrm{o}}<\kappa_{\mathrm{i}} .
\end{aligned}
$$

\section{Discussion and conclusion}

We proposed an analytical model based on Newtonian flow in capillaries to express the relationship between the stacking sequence of tissue and energy lost by fluid in its course through the VEP. The dependence of hydraulic resistance and effective permeability upon fluid-flow direction was established using ratios of porosities of subchondral bone, capillary bed and CEP into a biquadratic analytical function denoted by $\Delta \beta$, which could be nil, and it could alternate between positive and negative values.

In Ayotte et al. (2001), ovine VEP resistance to flow was lower for flow-out than for flow-in. This result corresponded to a positive value of $\Delta \beta$. According to our model, the ratio of capillary porosity $\phi_{\mathrm{cb}}$ over cartilage porosity $\phi_{\text {cep }}$ defined by $b$ corresponded to values greater than 0.5 .

With an asymmetric tether in a porcine animal model developed by us (Accadbled 2007), we found that effective permeability was greater for flow-out than for flow-in. This was confirmed by animal studies based on an ovine growing model (Accadbled, Laffosse et al. 2008). The differences were bolder in the central zone of the VEP, which corresponded to the location of the nucleus pulposus. The associated finding from our model was $\Delta \beta$ negative. In that case, the ratio $a$ of capillary porosity $\phi_{\mathrm{cb}}$ over subchondral bone porosity $\phi_{\mathrm{sb}}$ corresponded to values lower than 0.5 .

Another animal study concerned a scoliosis porcine model (Laffosse 2008; Odent et al. 2008). Discrepancies were observed between flow-in and flow-out permeabilities, but they were not proved significant. This case could reveal one of the singular values $b_{0}=1-a$ of our analytical model corresponding to a function $\Delta \beta$ close to zero. 
Finally, comparison with experimental results from the literature corroborated the findings from the analytical model unified by Equations (10). Assuming that the cartilage porosity was much lower than that of the subchondral bone, we saw that the modification of capillary bed porosity $\phi_{\mathrm{cb}}$ relative to cartilage and subchondral bone porosities could induce the alternation or cancellation of $\Delta \beta$ and it could consequently explain how the energy loss could be flow-direction dependent. Capillary bed obstruction, translated into a decrease of capillary porosity $\phi_{\mathrm{cb}}$ in the analytical model, could induce a sclerosis of the CEP, and by cascade could affect convective transports and, therefore, alter diffusion of nutriments. Potentially, this could result in a disorder of tissue homeostasis (Ayotte et al. 2000; Grignon et al. 2000).

Experimental studies allowed assuming that porosity ratios were dependant upon species, region of interest within the VEP and mechanical stimuli that conditioned remodelling of the vertebral segment, especially in conditions such as scoliosis. Our analytical model could support the main tendencies observed in vivo, but its formulation was dependant upon ratio of porosities scarcely reported in the literature, especially for pathological tissues. We obtained $a=0.1$ and $b=0.4$ using approximate values of capillary bed porosity $\phi_{\mathrm{cb}} \approx 0.02$, CEP porosity $\phi_{\text {cep }} \approx 0.05$ and subchondral bone porosity $\phi_{\mathrm{sb}} \approx 0.2$ (Cowin 2001; Ferguson et al. 2004). For these values, Equation (8) and Figure 2 confirmed that $\Delta \beta$ was negative meaning that exudation of fluid from the IVD was easier than absorption. According to phenomena observed in vivo, the mathematical solutions could evolve significantly, because the model was strongly dependant upon the ratio of CEP porosity over subchondral bone porosity. We also pointed out a singular value of 0.5 for ratios $a$ and $b$ for which absolute values of difference of flow resistance were maximal. Could these theoretical values be realistic in vivo, and how pathology could alter these values? These questions require further histology and imaging investigations, especially with pathological tissue. In any case, the analytical model allowed confirming that small perturbations of porosities of the VEP could induce significant modifications of convective transport in the vertebral segment.

The capillary bed was modelled using a rectilinear micro channel with constant cross-section. This is a simplified model and such connections might show tortuosity with evolving cross-sections in vivo. For a more complex description of the microarchitecture, a pure analytical modelling approach found its limits and the translation towards a numerical 3-D model could be suggested. Even if this perspective seemed attractive, the reliability of the computational model would be strongly dependant on the accuracy of the geometry segmentation and reconstruction, which would be challenging at this scale.

To implement our analytical approach. We assumed that flow rates were identical in and out to implement our analytical approach. The assumption was valid in quasistatic flows and also consistent with ex vivo experimental procedures (Ayotte et al. 2001; Laffosse et al. 2005; Accadbled, Ambard et al. 2008), but the relevance of the model could be enhanced taking into account the dynamic effects over the day and night cycle. This approach would require a more complete thermodynamic approach involving time distributions of loadings and induced fluid-structure interactions as well as energetic potentials, such as osmotic and electrochemical potentials, driving diffusive flows of nutriments and modifying relative pressure and flow rates.

Finally, we showed that the proposed analytical model based on fluid flow in capillary medium could contribute to the phenomenological analysis of convective flow through the VEP. It helped to obtain a plausible response to the question of dependence of energy loss on flow direction by fluid in its course through the VEP.

\section{Acknowledgements}

We acknowledge both the French Ministry of Education and Research, and the University Hospital of Toulouse for their support.

Conflict of interest. The authors hereby declare they have no conflict of interest.

\section{References}

Accadbled F. 2007. Contribution à l'analyse du transport convectif dans le segment vertébral: étude de la perméabilité macroscopique du plateau vertébral [PhD thesis]. [France]: University of Toulouse.

Accadbled F, Ambard D, de Gauzy JS, Swider P. 2008. A measurement technique to evaluate the macroscopic permeability of the vertebral end-plate. Med Eng Phys. 30(1):116-122.

Accadbled F, Laffosse JM, Ambard D, Gomez-Brouchet A, de Gauzy JS, Swider P. 2008. Influence of location, fluid flow direction, and tissue maturity on the macroscopic permeability of vertebral end plates. Spine. 33(6):612-619.

Ayotte DC, Ito K, Perren SM, Tepic S. 2000. Directiondependent constriction flow in a poroelastic solid: the intervertebral disc valve. J Biomech Eng. 122(6):587-593.

Ayotte DC, Ito K, Tepic S. 2001. Direction-dependent resistance to flow in the endplate of the intervertebral disc: an ex vivo study. J Orthop Res. 19:1073-1077.

Bibby SR, Jones DA, Ripley RM, Urban JP. 2005. Metabolism of the intervertebral disc: effects of low levels of oxygen, glucose, and $\mathrm{pH}$ on rates of energy metabolism of bovine nucleus pulposus cells. Spine. 30(5):487-496.

Cowin SC. 2001. Bone mechanics handbook. 2nd ed. Taylor \& Francis Ltd.

Dullien F. 1992. Porous media, fluid transport and pore structure. USA: Academic Press.

Ferguson SJ, Ito K, Nolte LP. 2004. Fluid flow and convective transport of solutes within the intervertebral disc. J Biomech. $37: 213-221$.

Grignon B, Grignon Y, Mainard D, Braun M, Netter P, Roland J. 2000. The structure of the cartilaginous end-plates in elder people. Surg Radiol Anat. 22(1):13-19. 
Grunhagen T, Wilde G, Soukane DM, Shirazi-Adl SA, Urban JP. 2006. Nutrient supply and intervertebral disc metabolism. J Bone Joint Surg Am. 88(Suppl 2):30-35.

Holm S, Maroudas A, Urban JP, Selstam G, Nachemson A. 1981. Nutrition of the intervertebral disc: solute transport and metabolism. Connect Tissue Res. 8:101-119.

Houben GB, Drost MR, Huyghe JM, Janssen JD, Huson A. 1997. Nonhomogeneous permeability of canine anulus fibrosus. Spine. 22(1):7-16.

Idelchik IE. 2001. Handbook of hydraulic resistance. 3rd ed. New York: Begell House Publishers.

Katz M, Hargens A, Garfin S. 1986. Intervertebral disc nutrition. Diffusion versus convection. Clin Orthop. 210:243-245.

Laffosse JM. 2008. Contribution à l'étude du transport convectif dans le segment vertébral scoliotique: mécanobiologie, micro-architecture et perméabilité des plateaux vertébraux [PhD thesis]. [France]: University of Toulouse.

Laffosse JM, Ambard D, Accadbled F, Gomez-Brouchet A, Fromentin A, Sales de Gauzy J, Swider P. 2005. Influence of location, fluid flow direction and bone tissue maturity on the permeability of vertebral end-plates. 51th Annual Meeting of Orthopedic Research Society, USA.

Nachemson A, Lewin T, Maroudas A, Freeman MA. 1970. In vitro diffusion of dye through the end-plates and the annulus fibrosus of human lumbar inter-vertebral discs. Acta Orthop Scand. 41:589-607.

Odent T, Cachon T, Peultier B, Gournay J, Jolivet E, Viguier E. 2008. Porcine scoliosis model based on animal growth created with minimal invasive off-set tethering. 43rd Annual
Meeting of Scoliosis Research Society, Salt Lake City, Utah, USA.

Rajasekaran S, Babu J, Arun R, Armstrong BR, Shetty AP, Murugan S. 2004. ISSLS Prize Winner: a study of diffusion in human lumbar discs: a serial magnetic resonance imaging study documenting the influence of the end-plate diffusion in normal and degenerate discs. Spine. 29:2654-2667.

Roberts S, Menage J, Urban JP. 1989. Biochemical and structural properties of the cartilage end-plate and its relation to the intervertebral disc. Spine. 14:166-174.

Roberts S, Menage J, Eisenstein SM. 1993. The cartilage endplate and intervertebral disc in scoliosis: calcification and other sequelae. J Orthop Res. 11:747-757.

Rohsenhow WM, Hartnett JP, Ganić EN. 1985. Handbook of heat transfer fundamentals. 2nd ed. McGraw-Hill Book Company.

Sélard E, Shirazi-Adl A, Urban JP. 2003. Finite element study of nutrient diffusion in the human intervertebral disc. Spine. 28(17): 1945-1953, discussion 1953.

Soukane D, Shirazi-Adl A, Urban J. 2007. Computation of coupled diffusion of oxygen, glucose and lactic acid in an intervertebral disc. J Biomech. 40:2645-2654.

Urban MR, Fairbank JC, Etherington PJ, Loh FL, Winlove CP, Urban JP. 2001. Electrochemical measurement of transport into scoliotic intervertebral discs in vivo using nitrous oxide as a tracer. Spine. 26(8):984-990.

Urban J, Smith S, Fairbank J. 2004. Nutrition of the intervertebral disc. Spine. 29:2700-2709. 